\title{
Henry Matthew: The father of modern clinical toxicology
}

\author{
${ }^{1}$ AT Proudfoot, ${ }^{2} \mathrm{LF}$ Prescott \\ ${ }^{1}$ Retired Consultant Physician in Toxicology; ${ }^{2}$ Emeritus Professor of Clinical Pharmacology, Edinburgh, UK
}

\begin{abstract}
Henry Matthew was appointed a consultant in the Royal Infirmary of Edinburgh in 1955, by which time he was a highly regarded general physician with an interest in cardiology. In 1964 he agreed, almost certainly reluctantly, to head the recently designated Regional Poisoning Treatment Centre, which he did until his retirement ten years later. Matthew quickly established himself as an authority in clinical toxicology, mainly from an unrivalled experience of treating poisoned patients, day-in and day-out, but also by publishing original research, letters and books. Such were his contributions that he is regarded as the father of clinical toxicology.
\end{abstract}

KEYWORDS Clinical toxicology, Henry Matthew, Regional Poisoning Treatment Centre, Royal Infirmary of Edinburgh, Scottish Poisons Information Bureau
Published online December 2009

Correspondence to AT Proudfoot, 8 Mortonhall Park Avenue, Edinburgh EHI7 8BP, UK

tel. +44 (0) I3I 6643942 e-mail alexproudfoot@mortonhall. demon.co.uk

DECLARATION OF INTERESTS No conflict of interests declared.

\section{INTRODUCTION}

The death in 1997 of Henry Matthew (Figure I) passed unremarked in his own land, a sad omission given his substantial contributions to the emerging discipline of clinical toxicology. Redress is required.

Henry Johnston Scott Matthew was born in Edinburgh on 22 March 1914. After schooling at Edinburgh Academy he studied medicine at Edinburgh University, graduating in the top five in the final examinations of 1937.' There followed house posts in the Royal Infirmary of Edinburgh and Great Ormond Street Hospital, London, but a career in surgery was cut short when he was called for service in the Second World War. After being invalided out of the war and following a period of recovery, he went into general practice and became a clinical tutor in medicine at the Royal Infirmary of Edinburgh in 1945. In time he rose through the career grades until he was appointed a consultant physician to the Royal Infirmary five years later. By the early 1960s Matthew was a superb general physician with an interest in cardiology, and was rated very highly as a teacher by students in their clinical years. But his career was about to undergo major change.

\section{THE MOVE TO CLINICAL TOXICOLOGY}

The stimulus for that change was the decision of the managers of the Royal Infirmary to designate the ward for incidental delirium (Ward 3) a Regional Poisoning Treatment Centre (RPTC) in response to a report issued by the Ministry of Health in England and the Scottish Home and Health Department. Matthew was given no choice: he returned from holiday to find he had been nominated by his peers in the Physicians' Committee to take charge of the renamed unit, although he was

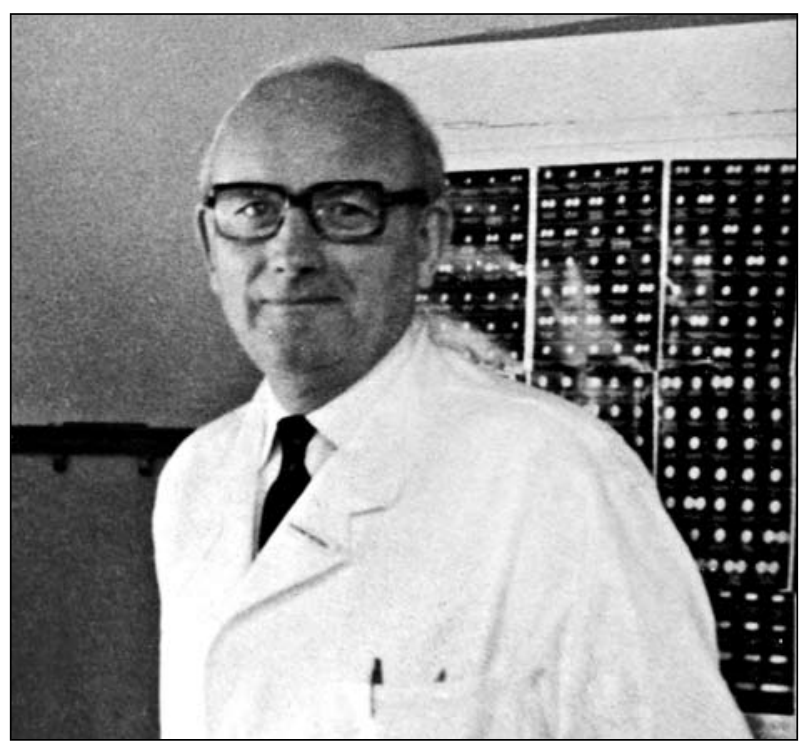

FIGURE I Henry Matthew in the doctors' room of the Regional Poisoning Treatment Centre, circa May 1973. In the background is a chart to aid identification of white tablets.

probably no better suited to the task than any other consultant in the hospital. Objecting, he wrote a letter to the Medical Superintendent and set out to deliver it personally. On the way he met John Halliday Croom, a long-standing friend and consultant colleague.' We do not know what passed between them, only that the letter was not delivered and, in 1964, Matthew launched himself into clinical toxicology. It was an opportune moment: he had given up private practice, a UK-wide poisons information service had just been established with a centre in Edinburgh and the Medical Research Council had recently opened a Unit for the Epidemiology of Psychiatric Illness at the Royal Edinburgh Hospital, with self-harm one of its major concerns. 


\section{CLINICAL TOXICOLOGY IN THE EARLY I960s}

At this time few physicians were enamoured of poisoned patients. The prospect of caring for them was 'frightening', mainly because no one knew how,' and because intensive care was in its infancy and far from widely available. While most patients would recover uneventfully, others were prone to deteriorate, often unexpectedly and dramatically, due to complications such as obstructed airways, seizures, intractable hypotension and cardiac dysrhythmias, often in combination. Atelectasis and pneumonia also took their toll. ${ }^{2}$

However, there had been advances in the management of acute poisoning elsewhere. The first resuscitation centre dedicated to poisoned patients had been opened in Bispebjerg Hospital, Copenhagen, in 1949. In the south of England, a similar unit, the North-East Metropolitan Regional Barbiturate Unit, was set up in Oldchurch Hospital, Romford, in the 1950s. The Danish centre, with Swedish input, published the outcome of its management of barbiturate poisoning two years after it opened ${ }^{3}$ and was to produce many more papers on the subject before 1965, by which time the 'Scandinavian method' of treating barbiturate poisoning, in particular, was firmly established. It involved applying to unconscious patients the principles practised by anaesthetists and avoiding the use of central nervous system stimulants such as nikethamide and bemegride, the value of which was finally discredited. ${ }^{4}$

Several textbooks were also available. Pertinent to Britain was Clinical toxicology, a tome of nearly 800 pages published in 1957 and the work of Sidney Locket, physician-in-charge of the Romford Barbiturate Unit. ${ }^{5}$ Already, the ward for incidental delirium at the Edinburgh Royal Infirmary awaited publication of its first research into clinical toxicology, Beveridge et al. on salicylate poisoning. ${ }^{6}$

\section{ESTABLISHING CREDENTIALS}

Whatever reservations he may have had initially, they did not show and Matthew confronted clinical toxicology head on. At some early point in his new field he visited the Intoxication Center in Copenhagen and was convinced by the Scandinavian method, although he preferred to term it intensive supportive therapy. This was hardly surprising: the Danes had reduced the mortality from barbiturate poisoning from almost $25 \%$ to less than $2 \%$ in ten years, ${ }^{7}$ an unrivalled feat. But, however important that visit, a physician of Matthew's abilities was going to learn much more and more rapidly simply from caring for poisoned patients day-in and day-out and there was to be no shortage of them as numbers rose, year on year.

Matthew led the junior medical staff, nursing staff and medical students on a round of the poisoned patients at 08.30, every morning of the week. The seriously intoxicated were visited more frequently. In addition to ad hoc contacts concerning patients whose care posed problems, he established formal weekly meetings with nurses, psychiatrists, social workers and health visitors and with clinical biochemists to review the laboratory abnormalities and analytical toxicology findings of the previous week. Under his stimulus and guidance there was an enthusiastic and active journal club to discuss recently published papers on poisoning and a weekly visit to the X-ray department to review the films of inpatients and outpatients with a consultant radiologist. As a result of these activities, Matthew quickly grasped the major problems facing clinical toxicology and set about addressing them. He established his authority in this field by publishing original research, a book and numerous letters to journals.

\section{RESEARCH}

It seems strange, however, that clarifying the role of gastric aspiration and lavage in the management of those who had ingested poisons was high on Matthew's research agenda. Lavage had been abandoned in Denmark in 1946, ${ }^{7}$ although, later, aspiration was not considered inappropriate if the patient presented within one to two hours of ingestion and the pharyngeal and laryngeal reflexes remained intact. ${ }^{3}$ Lavage had been rejected on the basis of a study that showed it recovered very little poison from the stomach and, just as important, because charcoal particles added to the lavage fluid were found in the lungs of eight out of nine consecutive individuals who died from barbiturate overdosage. ${ }^{8}$

Matthew considered this study flawed. The method used to determine the amount of drug recovered involved crystallising it out of the lavage fluid then weighing it, 'an excellent means for identification purposes... but of little value for quantification'. For this reason he considered a new appraisal necessary and it is a remarkable testament to his determination and, where necessary, his power of persuasion, that 'during a fivemonth period in 1965 gastric aspiration and lavage was carried out in all patients [254 of them]... who had ingested drugs or poisons of any type'.' Had conscious patients known the bore of the gastric tube Matthew considered essential if lavage was to be effective, many might have refused. Not for him the clear, thin nasogastric tubes beloved of television medical soaps; instead, a quite stiff red rubber one, English 30 gauge, with an external diameter of approximately $2 \mathrm{~cm}$ !

The recommendations Matthew made in respect of barbiturate overdosage in the light of his research ${ }^{10}$ were widely accepted and welcomed by clinical staff, who were only too happy to have clear guidance on a procedure that most found messy, time-consuming and unpleasant for all concerned. However, the conclusion that gastric aspiration and lavage were indicated in 
salicylate poisoning, regardless of the ingestion/ presentation interval, was to be more controversial. Much later, some felt the data did not warrant the recommendation."

Original contributions on the general management of acute poisoning, ${ }^{12}$ the need (or otherwise) for prophylactic antibiotics in unconscious patients, ${ }^{13}$ forcing a diuresis in salicylate intoxication, ${ }^{14}$ and the features of tricyclic antidepressant poisoning ${ }^{15}$ followed. The numbers of patients Matthew treated emphasised his experience and authority; for example, 776 barbiturate overdoses treated over two years ${ }^{16}$ and 100 cases of poisoning with tricyclic antidepressants. ${ }^{15}$

The centralisation of poisoned patients also ensured that when new therapeutic agents began to be prescribed, particularly hypnotics and psychotropic drugs, Matthew was able to publish the consequences of acute overdosage with them at a speed that was unheard of and in greater numbers than was possible elsewhere; for example II6 cases of methaqualone (Mandrax ${ }^{\circledR}$ ) poisoning ${ }^{17}$ and 27 with nitrazepam. ${ }^{18}$ Trainees in the RPTC were also encouraged to publish, but only when their manuscripts survived Matthew's critical eye and red pen. Notable among them was a paper on skin blistering complicating barbiturate poisoning, ${ }^{19}$ a perennial source of fascination, and the first reported deaths from paracetamol (acetaminophen) overdose. ${ }^{20}$

\section{Letters}

Letters to the main British journals of the day, sometimes with co-authors, were also a means by which Matthew established his authority in clinical toxicology. He was often scathing. A leading article on forced diuresis for acute salicylate poisoning was 'vague, unhelpful and inaccurate. The issue [of treatment was] confused by meaningless comparison with barbiturate poisoning. ${ }^{21}$ Writers about paracetamol poisoning also came into his line of fire. Some, 'in their enthusiasm for haemoperfusion through charcoal, manage to introduce considerable confusion regarding the safety of the method', ${ }^{22}$ while others who had employed haemodialysis seemed to invoke dismay: 'Experts among your readers will doubtless be commenting on the cumbersome, time-consuming method of determination of the plasma-paracetamol, the unwarranted deductions quoted from other papers, and the nebulous postulates. ${ }^{23}$ Of course, his criticism was usually fully justified.

\section{Books}

Matthew never forgot his prime function, that of a bedside clinician and teacher. After no more than three years as the head of the RPTC the first edition of Treatment of common acute poisonings appeared in print with Lex Lawson as co-author. ${ }^{24}$ It was small, only I5I pages (including the index) long, and in a format 7.5 inches high and 5 wide. The dimensions were deliberate: the book was intended to fit easily in the pockets of the long white coats worn by hospital medical staff at the time. A reviewer for The Lancet thought it a compact little book which 'spell[ed] out admirably the basic principles of treatment and their application to the common poisonings encountered in Edinburgh'. It was 'good value - well worth reading by the student but of less certain help to the resident or consultant' and criticised for 'virtually dismiss[ing] analytical toxicology'. ${ }^{25}$ The book 'sold like mad' in many countries around the world but not in North America' and went on to be published in three further editions.

Later, Matthew edited a multi-author book on acute barbiturate poisoning on behalf of the Excerpta Medica Foundation of Amsterdam. ${ }^{26}$

\section{MYTHS AND MISCONCEPTIONS}

Arguably, Matthew's major contribution to the literature was his attack on so-called authorities on clinical toxicology and his exposure of the myths and misconceptions that had accumulated over the decades to encrust the subject. ${ }^{27}$ They explained why 'to some extent... clinicians may be excused for their confusion in dealing with poisoned patients'. However,'the problem is now [in 197I] of such magnitude that indifference can no longer be condoned'. ${ }^{27}$ Pharmacologists, forensic pathologists and neurologists 'who rarely have responsibility for poisoned patients' yet who wrote on the subject with apparent authority, were castigated and journal editors criticised for the anonymity of those who wrote their leading articles and for failing to obtain sufficiently expert opinion so that toxicological nonsense appeared in print.

Nothing raised Matthew's ire more than case reports that lacked analytical data yet claimed that whatever medical intervention was employed must have been effective simply because the patient survived. The editors of medical textbooks were also taken to task for allocating too few pages to what was an enormous and increasingly important topic. Specific issues were debunked, among them the presence of a cherry-pink skin colour in carbon monoxide poisoning, the rarity of hyperventilation in that poisoning resulting in a recommendation to administer varying percentages of carbon dioxide along with oxygen to stimulate respiration, the frequency of coma in salicylate intoxication and inappropriate analytical methods. ${ }^{27}$

He also increased awareness of the work of his colleagues in the RPTC: that poisoned patients with flat electro-encephalograms (EEGs) usually recovered unscathed and casting doubt on the concept of barbiturate 'automatism' in which a hypnotic dose was alleged to induce such forgetfulness that it could be repeated and repeated until coma supervened. 
Matthew's 'Myths and misconceptions' paper was a wide-ranging and forthright assault justified by the belief that it was 'vital that clinical toxicology in all its aspects be founded on sound observations and scientific measurements' and a necessary prelude to achieving these objectives. ${ }^{27}$

\section{CHANGE}

During Matthew's career in toxicology there were striking changes in the pattern of agents used for selfpoisoning. Barbiturate overdosage declined and virtually disappeared as prescribing of benzodiazepine hypnotics and sedatives became commonplace. The number of paracetamol overdoses began to escalate as those of aspirin declined because of concern that it caused upper alimentary bleeding. In the year or two before his retirement, Matthew was to see his unit introduce cysteamine, the first antidote to protect against paracetamol-induced hepatotoxicity. ${ }^{28}$ Increasing numbers of patients intoxicated with tricyclic antidepressants posed new challenges, while admissions for carbon monoxide poisoning fell when coal gas was supplanted by natural gas for cooking and heating.

Poisoning with a new herbicide, paraquat, caused both excitement and distress. No other toxin induced such terrible effects. As little as a mouthful, most of which had been spat out, could be fatal. If the patients survived 24 hours they usually developed painful mouth, throat and laryngeal ulcers that severely limited eating, drinking and speaking, and went into renal failure. After that, symptoms secondary to rapidly progressive pulmonary fibrosis added to the misery, all the worse because the victim was conscious throughout and because of the knowledge that oxygen administration would only accelerate the lung damage. Overall, mortality was about $65 \%$ and some patients took three weeks or longer to die, their carers powerless to prevent it. On the basis of others' animal research and hypotheses, Matthew tried bentonite, propranolol and superoxide dismutase, but to no avail. Circumstances allowed him to go much further with his first patient poisoned (accidentally) with paraquat, a boy of 16 from the island of Lewis. He was to be Britain's first and the world's 12th recipient of a single lung transplant, ${ }^{29}$ but the transplant was damaged by herbicide still present in his body, with the inevitable result. ${ }^{30}$

In 1964 Matthew was appointed to serve on the UK government's Interdepartmental Committee on Drug Addiction. Little is known of his involvement with the European Association of Poison Control Centres (now the European Association of Poisons Centres and Clinical Toxicologists), but at the end of December 1968 he was listed as one of 128 Charter Members of the American Academy of Clinical Toxicology. ${ }^{31}$ His growing international reputation attracted a stream of visitors to the RPTC from overseas.

\section{THE SCOTTISH POISONS INFORMATION BUREAU}

The Scottish Poisons Information Bureau (SPIB) was inaugurated on 2 September 1963, with Dr Harold V Street as its director, ${ }^{32}$ and similar units opened in London and the capitals of Wales and Northern Ireland around the same time. Street was an analytical chemist on the staff of the Department of Forensic Medicine of the University of Edinburgh and this was the initial location of the SPIB. However, having a service for the living operating from a department preoccupied with the dead and one that was not staffed 24 hours a day was clearly not ideal. When Street resigned in July 1965, the service logically moved to the RPTC with Matthew as its director.

In those days the poisons information database was a paper system, the data on each substance or product being typed on a standardised sheet which was filed alphabetically in the appropriate large register. The London centre was responsible for producing new entries and updating old ones as necessary, then circulating them to the other centres. When a batch reached Edinburgh, Matthew would soon be seen going through them, one by one, and those that did not come up to his high standards were returned with comments in red ink. The frequency with which this happened could not have endeared him to those whose labours were being criticised.

\section{CONCLUSION}

Clinical toxicology could only become a distinct medical discipline when the number of human poisonings increased considerably and their treatment was centralised in specifically designated units. It was in this field that Henry Matthew excelled and led until his retirement at the age of 60 . For a man who had published only two papers earlier, he made an enormous contribution. In little more than ten years he transformed the image of clinical toxicology, setting a discipline beset by diagnostic, therapeutic and laboratory complexities on a clear path to becoming evidence-based and medically respectable. Lack of discipline in respect of the appropriateness of the analytical methods used and failure to appraise critically both the evidence and the deductions from it, would no longer be acceptable. He is truly the "father of modern clinical toxicology.".

Acknowledgements The authors are grateful to Dr GW Beveridge for sharing his memories of Henry Matthew in the years before he took charge of the RPTC. 


\section{REFERENCES}

I Royal College of Physicians of Edinburgh. Video-tape of Henry Matthew interviewed by Dr MA Eastwood. Edinburgh: RCPE; 1996.

2 Jacobsen $P$. Cause of death in narcotic intoxication in recent years. Dan Med Bull 1963; 10:115-6.

3 Nilsson E. On treatment of barbiturate poisoning: a modified clinical aspect. Acta Med Scand 1951; 253:1-127.

4 Wax PM. Analeptic use in clinical toxicology: a historical perspective. J Toxicol Clin Toxicol 1997; 35:203-9. doi:I0.3 I09/I556365970900I I 95

5 Locket S. Clinical toxicology: the clinical diagnosis and treatment of poisoning. London: Henry Kimpton: 1957.

6 Beveridge GW, Forshall W, Munro JF et al. Acute salicylate poisoning in adults. Lancet 1964; I:I406-9. doi:I0.10I6/SOI406736(64)9198I-6

7 Clemmesen C. Treatment of narcotic intoxication. Results and principles of the 'Scandinavian' method, especially concerning stimulation. Dan Med Bull 1963; 10:97-9.

8 Harstad E, Møller KO, Simesen MH. [The value of gastric lavage in the treatment of acute poisoning.] Acta Med Scand 1942; I I 2:4785I4. In German.

9 Matthew $\mathrm{H}$. Acute poisoning: a review of I,542 patients treated in 1964-65. [MD thesis.] Edinburgh: University of Edinburgh; 1966.

10 Matthew H, Mackintosh TF, Tompsett SL et al. Gastric aspiration and lavage in acute poisoning. BMJ 1966; I:1333-7. doi:I0.II36/ bmj. I.5499.1333

II Haulman J, Robertson WO. Syrup of ipecac in 1993. Drug Safety 1993; 9:79-84. doi:I0.2165/00002018-199309020-00001

12 Matthew H.Acute poisoning. Scot Med J 1966; I I:I-6.

I3 Mackintosh TF, Matthew H. Do unconscious poisoned patients need prophylactic penicillin? Lancet 1965; I:1252-4. doi:10.1016/ Sol40-6736(65)91894-5

14 Lawson AAH, Proudfoot AT, Brown SS et al. Forced diuresis in the treatment of acute salicylate poisoning in adults. $Q \mathrm{~J}$ Med 1969; 38:31-48.

15 Noble J, Matthew $\mathrm{H}$. Acute poisoning by tricyclic antidepressants: clinical features and management of 100 patients. J Toxicol Clin Toxicol 1969; 2:403-2I. doi:10.3109/15563656908990950

I6 Matthew H, Lawson AAH. Acute barbiturate poisoning - a review of two years' experience. Q J Med 1966; 35:539-52.
17 Matthew H, Proudfoot AT, Brown SS et al. Mandrax poisoning: conservative management of 116 patients. BMJ 1968; 2:10I-2. doi:I0.I I36/bmj.2.5597.I0I

I 8 Matthew H, Proudfoot AT, Aitken RCB et al. Nitrazepam - a safe hypnotic. BMJ 1969; 3:23-5. doi:I0.I I36/bmj.3.566I.23

19 Beveridge GW, Lawson AAH. Occurrence of bullous lesions in acute barbiturate intoxication. BMJ 1965; I:835-7. doi:10.II36/ bmj.I.5438.824

20 Davidson DGD, Eastham WN. Acute liver necrosis following overdose of paracetamol. BMJ 1966; 2:497-9. doi:I0.1I36/ bmj.2.55 I 2.497

2I Matthew H, Proudfoot AT, Brown SS et al. Acute salicylate poisoning. Lancet 1969; I:I312. doi:10.1016/S0140-6736(69)92243-0

22 Matthew $\mathrm{H}$. Removal of paracetamol by haemoperfusion. Lancet 1973; I:494. doi:10.1016/S0140-6736(73)91934-X

23 Matthew $\mathrm{H}$. Haemodialysis in paracetamol self-poisoning. Lancet 1972; 2:607. doi:I0.1016/S0I40-6736(72)920II-9

24 Matthew H, Lawson AA. Treatment of common acute poisonings. Edinburgh: E \& S Livingstone; 1967.

25 Anonymous. Treatment of common acute poisonings. Lancet 1968; I:74.

26 Matthew $\mathrm{H}$, editor. Acute barbiturate poisoning. Amsterdam: Excerpta Medica Foundation: 197I.

27 Matthew $\mathrm{H}$. Acute poisoning: some myths and misconceptions. BMJ 197I; I:519-22. doi:I0.II36/bmj.I.5748.5 I9

28 Prescott LF, Newton RW, Swainson CP et al. Successful treatment of severe paracetamol overdosage with cysteamine. Lancet 1974; I: 588-92. doi:I0.I0I6/S0I40-6736(74)92649-X

29 Wildevuur $\mathrm{CRH}$, Benfield JR. A review of 23 human lung transplantations by 20 surgeons. Ann Thorac Surg 1970; 9:489-5I 5.

30 Matthew H, Logan A, Woodruff MF et al. Paraquat poisoning - lung transplantation. BMJ 1968; 3:759-63. doi:I0.I I36/bmj.3.562I.759

3I Thoman M. Detailed history of the American Academy of Clinical Toxicology. AACTion 2008; 18:3-7. Available from: http://www. clintox.org/documents/newsletters/08 December AACT News.pdt

$32 \mathrm{LHBI} / 6 \mathrm{I} / 33$. First report of the Scottish Poisons Information Bureau Edinburgh: Centre for Research Collections, University of Edinburgh; 1964. 